\title{
Prevalence and Recovery of Olfactory Dysfunction in 1,363 patients with coronavirus disease 2019: A Multicenter Longitudinal Study.
}

Jerome Lechien ( $\boldsymbol{\nabla}$ Jerome.Lechien@umons.ac.be)

Department of Otorhinolaryngology and Head and Neck Surgery, CHU de Bruxelles, CHU Saint-Pierre, School of Medicine, Universit\&\#x00E9; Libre de Bruxelles, Brussels, Belgium. https://orcid.org/00000002-0845-0845

\section{Carlos Chiesa-Estomba}

San Sebastian University

\section{Eline Beckers}

Clinique de L'Europe

\section{Vincent Mustin}

Clinique de l'Europe

\section{Morgane Ducarme}

EPICURA

\section{Fabrice Journe}

UMONS

\section{Arnaud Marchant}

ULB

\section{Lionel Jouffe}

Bayesia https://orcid.org/0000-0003-0999-1835

\section{Maria Barillari \\ Uni Campania}

\section{Stephane Hans}

Foch Hospital

\section{Sven Saussez}

University of Mons https://orcid.org/0000-0002-3655-1854

\section{Article}

Keywords: COVID-19, Coronavirus, SARS-CoV-2, Anosmia, Hyposmia, Olfactory, Smell, Recovery, Serology

Posted Date: July 10th, 2020

DOl: https://doi.org/10.21203/rs.3.rs-38504/v1 
License: (c) (i) This work is licensed under a Creative Commons Attribution 4.0 International License. Read Full License 


\section{Abstract}

Olfactory dysfunction (OD) is a key symptom of coronavirus disease 2019 (COVID-19). Currently, a few data are available about the recovery of OD after the infection resolution. In this study, we investigated both prevalence and recovery rate of OD with subjective and objective clinical tools in 2,581 patients. First, our data showed that the prevalence of OD was significantly higher in mild form (85.9\%) compared with moderate-to-critical forms $(4.5-9.7 \% ; \mathrm{p}=0.001)$. Second, focusing on patients with OD who completed the 2-month follow-up period $(\mathrm{N}=1,363)$, we observed that 328 patients $(24.1 \%)$ did not subjectively recover olfaction 60 days after the onset of the dysfunction. The mean duration of self-reported OD was $21.6 \pm 17.9$ days. Third, the objective olfactory evaluations performed on a subset of patients $(\mathrm{N}=233)$ reported hyposmia or anosmia in $54.7 \%$ and $36.6 \%$ of mild and moderate-to-critical forms, respectively $(p=0.001)$. At the end of follow-up, $15.3 \%$ of anosmic/hyposmic patients did not objectively recover olfaction. The higher baseline severity of objective olfactory evaluations was strongly predictive of persistent OD $(\mathrm{p}<0.001)$. OD disappeared in $75 \%$ to $85 \%$ of patients regarding self-reported or objective olfactory evaluations.

\section{Introduction}

As of June 24th 2020, there have been 9 million confirmed cases of coronavirus disease 2019 (COVID-19) worldwide, with 469,587 confirmed deaths. ${ }^{1}$ The clinical picture of the infection may vary regarding the disease severity and usually includes general, otolaryngological and neurological symptoms. ${ }^{2,3}$ The olfactory dysfunction (OD) is one of the most prevalent symptoms. ${ }^{2}$ The prevalence of OD may vary regarding the clinical setting, with rates of total loss of smell as high as $70 \%$ in patients with mild COVID19 form. ${ }^{2,4,5}$ The prevalence of OD in moderate-to-critical COVID-19 forms was poorly investigated. Moreover, there is, to date, a paucity of studies prospectively studying the recovery rates of smell sense in COVID-19 patients.

The aim of this study is to investigate both prevalence and recovery of OD in COVID-19 patients through subjective and objective clinical tools.

\section{Methods:}

Five European local ethics committees approved the study protocol (HAP2020-011; CHUSP20032020; EpiCURA-2020-2303, CHUC-P20/30 - 24/03-B325-2020; J.Bordet Institute:CE3137). The electronic informed consent was obtained.

\section{Subjects \& Setting}

From March 22, to June 3, 2020, 2,581 ambulatory and hospitalized patients with laboratory-confirmed diagnosis of COVID-19 (nasal swabs-RT-PCR) were consequently identified from 18 European hospitals. Among them, 1,916 patients reported subjective OD (74.9\%), defined as partial of total loss of smell. The 
definition of mild, moderate, severe and critical patients was based on the COVID-19 Disease Severity Scoring of World Healthy Organization. ${ }^{6}$ Mild patients were defined as patients without evidence of viral pneumonia or hypoxia and were commonly home-managed and followed. Moderate COVID-19 patients had clinical signs of pneumonia (fever, cough, dyspnea, fast breathing) but no sign of severe pneumonia (including SpO2 $\geq 90 \%$ on room air). Severe COVID-19 patients were defined as individuals with clinical signs of pneumonia plus one of the following: respiratory rate $>30$ breaths/min; severe respiratory distress; or Sp02 $<90 \%$ on room air. According to the center and the availability of local healthcare resource, moderate and severe patients were home-managed (moderate) or hospitalized in non-intensive care units (ICU) versus ICU. Patients with critical disease had acute respiratory distress syndrome (ARDS), sepsis or septic shock and were hospitalized in ICU. Patients with OD were followed to assess the recovery olfactory rates and the duration of OD.

\section{Epidemiological and Clinical Outcomes}

Epidemiological (gender, age, ethnicity) and clinical data (comorbidities and symptoms) were collected with a standardized online questionnaire at the end of the disease (defined as the general symptom resolution) or at the hospital discharge. Both patients (home-managed) and physicians (hospitalized patients) may fulfill the questionnaire. For patient who completed the study, olfactory and gustatory questions were based on the smell and taste component of the National Health and Nutrition Examination Survey (Appendix 1). 7,8

A subset of patients (EpiCURA Hospital, Belgium \& Foch Hospital, Paris, France) benefited from objective olfactory tests within the 2 (mild, moderate) or 3 (severe to critical) weeks of the onset of the olfactory disease. Olfactory objective evaluations consisted of Sniffin'Sticks tests (Medisense, Groningen, Netherlands), which is a standardized and validated psychophysical olfactory evaluation using 16 smell pens. The patient had to choose the adequate term describing the smell between 4 given options. ${ }^{7}$ The total score ranges from 0 (no olfaction) to 16 (perfect olfaction). Regarding results, three categories were defined: normosmia (score between 12-16), hyposmia (score between 9-11) and anosmia (score<9). ${ }^{9}$ Patients with hyposmia or anosmia were invited to attend for repeated evaluation with Sniffin'Sticks until scores returned to normal levels. Patients who benefited from psychophysical olfactory evaluation also fulfilled the French version of the sinonasal outcome tool-22 (SNOT-22). ${ }^{10}$ More details about the data collection, inclusion and exclusion criteria are available in the flow chart (Fig. 1).

\section{Biology and Imaging Findings}

The following admission outcomes were collected from the hospitalized patients: 02 saturation, chest computed tomography findings and biology, including blood formula, liver, renal, heart functions, inflammatory molecules and ionogram. The 1-month serology $(\mathrm{IgG})$ has been realized in patients who benefited from objective olfactory evaluations.

\section{Statistical Analyses}


Statistical analyses were performed using the Statistical Package for the Social Sciences for Windows (SPSS-v22,0; IBM Corp, Armonk, NY, USA). The outcome comparison between severity patient groups and the evolution of olfactory evaluations through the follow-up period were made through Kruskal-Wallis, Mann-Whitney U test, Wilcoxon Rank test and Chi-square. The relationship between epidemiological, clinical and olfactory outcomes was analyzed through multivariate analysis. According to the WHO classification, the statistics were realized considering 3 groups: mild, moderate, and severe-to-critical patients.

\section{Results:}

A total of 2,581 patients fulfilled the baseline evaluations, including 2,194 (85.0\%), $110(4.3 \%)$ and 277 $(10.7 \%)$ patients with mild, moderate, severe-to-critical COVID-19, respectively. There were 1,624 females (62.9\%). The proportion of female was higher in mild patient group compared to other groups $(p=0.001$, Table 1). The following ethnicities were represented: Caucasian (83.6\%), South American (11.6\%), Asian (1.2\%), North African (1.2\%), Black African (0.7\%) and mixing/other (1.5\%). The epidemiological and clinical features of patients are reported in Tables 1 and 2. 
Table 1

Epidemiological \& Clinical Characteristics of Patients.

\begin{tabular}{|c|c|c|c|c|}
\hline \multirow[t]{2}{*}{ Characteristics } & All Patients & Mild & Moderate & Severe \& Critical \\
\hline & $N=2,581$ & $N=2,194$ & $N=110$ & $N=277$ \\
\hline Age (y - Mean; SD) & $44.5 \pm 16.4$ & $41.9 \pm 13.0$ & $68.8 \pm 16.1$ & $71.9 \pm 13.7$ \\
\hline Gender (F/M) & $1624 / 957$ & $1455 / 739$ & $52 / 58$ & $117 / 160$ \\
\hline \multicolumn{5}{|l|}{ Comorbidities } \\
\hline Hypertension & $414(16.0)$ & $173(7.9)$ & $61(55.5)$ & $180(65.0)$ \\
\hline Current Smoker & $351(13.6)$ & $281(12.8)$ & $18(16.4)$ & $52(18.8)$ \\
\hline Asthma & $170(6.6)$ & $137(6.2)$ & $11(10.0)$ & $22(7.9)$ \\
\hline Diabetes & $148(5.7)$ & $41(1.9)$ & $27(24.5)$ & $80(28.9)$ \\
\hline Reflux or gastric ulcer & $120(4.6)$ & $87(4.0)$ & $12(10.9)$ & $21(7.6)$ \\
\hline Heart problems & $102(4.0)$ & $40(1.8)$ & $13(11.8)$ & $49(17.7)$ \\
\hline Kidney Insuffisiency & $57(2.2)$ & $10(0.5)$ & $8(7.3)$ & $39(14.1)$ \\
\hline Neurological Disease & $67(2.6)$ & $14(0.6)$ & $10(9.1)$ & $43(15.5)$ \\
\hline Respiratory insuffisiency & $65(2.5)$ & $11(0.5)$ & $11(10.0)$ & $43(15.5)$ \\
\hline Liver Insuffisiency & $34(1.3)$ & $17(0.8)$ & $6(5.5)$ & $11(4.0)$ \\
\hline \multicolumn{5}{|l|}{ Symptoms (N - \%) } \\
\hline Olfactory dysfunction & $1916(74.2)$ & $1884(85.9)$ & $5(4.5)$ & $27(9.7)$ \\
\hline Cough \& sticky mucus/phlegm & $1545(59.9)$ & $1266(57.7)$ & $52(47.3)$ & $227(81.9)$ \\
\hline Arthralgia \& myalgia & $1400(54.2)$ & $1340(61.0)$ & $14(12.7)$ & $46(16.6)$ \\
\hline Asthenia, anorexia or confusion & $1351(52.3)$ & $1042(47.5)$ & $57(51.8)$ & $252(91.0)$ \\
\hline Dyspnea & $1293(50.1)$ & $995(45.4)$ & $67(61.0)$ & $231(83.4)$ \\
\hline Gustatory dysfunction & $1182(45.8)$ & $1178(53.7)$ & $2(1.8)$ & $2(0.7)$ \\
\hline Fever $\left(>38 \mathrm{C}^{\circ}\right)$ & $1188(46.0)$ & $880(40.1)$ & $62(56.4)$ & $246(88.8)$ \\
\hline
\end{tabular}

Table 1 footnotes: Abbreviations: $\mathrm{F} / \mathrm{M}=$ female/male; $\mathrm{N}=$ number; $\mathrm{SD}=$ standard deviation. 
Table 2

Imaging and Biological Features of Moderate-to-critical Patients.

\begin{tabular}{|c|c|c|}
\hline & Moderate & Severe-to-critical \\
\hline Clinical Features & $N=110$ & $N=277$ \\
\hline \multicolumn{3}{|c|}{ Chest CT-scan findings (Lung Involvement) } \\
\hline Typical COVID-19 pneumonia & $67(60.9)$ & $157(56.7)$ \\
\hline Suspicion & $33(30.0)$ & $69(29.9)$ \\
\hline Negative & $10(9.1)$ & $51(18.4)$ \\
\hline \multicolumn{3}{|l|}{ Biology Admission Features } \\
\hline \multicolumn{3}{|l|}{ Blood Formula } \\
\hline Hemoglobin (g/dL) & $13.2 \pm 2.3$ & $13.0 \pm 2.2$ \\
\hline Neutrophils $\left(10^{\wedge} 3 / \mu \mathrm{l}\right)$ & $6.1 \pm 3.8$ & $7.1 \pm 4.7$ \\
\hline Lymphocytes $\left(10^{\wedge} 3 / \mu \mathrm{l}\right)$ & $1.2 \pm 0.7$ & $1.0 \pm 1.0$ \\
\hline Patelets $\left(10^{\wedge} 3 / \mu \mathrm{l}\right)$ & $247.3 \pm 104.9$ & $223.7 \pm 104.7$ \\
\hline \multicolumn{3}{|l|}{ Liver Function } \\
\hline GOT & $47.0 \pm 47.2$ & $106.6 \pm 593.8$ \\
\hline GPT & $38.1 \pm 42.4$ & $57.8 \pm 250.9$ \\
\hline GGT & $80.4 \pm 129.0$ & $81.4 \pm 91.8$ \\
\hline Alkalin phosphatase & $98.3 \pm 90.4$ & $92.0 \pm 62.4$ \\
\hline Total Bilirubin (mg/dL) & $0.8 \pm 1.6$ & $0.6 \pm 0.5$ \\
\hline \multicolumn{3}{|l|}{ Heart Biology } \\
\hline Troponin & $16.8 \pm 38.7$ & $45.1 \pm 132.3$ \\
\hline CPK & $255.9 \pm 598.5$ & $482.5 \pm 1772.4$ \\
\hline \multicolumn{3}{|l|}{ Renal Function } \\
\hline Creatinin (mg/dL) & $1.2 \pm 1.0$ & $1.6 \pm 1.6$ \\
\hline Urea $(\mathrm{mg} / \mathrm{dL})$ & $45.1 \pm 33.4$ & $59.0 \pm 40.2$ \\
\hline LDH (UI/L) & $315.3 \pm 141.8$ & $453.0 \pm 667.1$ \\
\hline \multicolumn{3}{|l|}{ Inflammatory Molecules/other } \\
\hline CRP (mg/L) & $68.8 \pm 66.1$ & $115.9 \pm 93.9$ \\
\hline
\end{tabular}




\begin{tabular}{|lll|}
\hline & Moderate & Severe-to-critical \\
\hline D-Dimer $(\mu \mathrm{g} / \mathrm{L})$ & $276.3 \pm 705.2$ & $695.3 \pm 1543.4$ \\
\hline lonogram & & \\
\hline $\mathrm{Na}+(\mathrm{mmol} / \mathrm{L})$ & $135.6 \pm 14.0$ & $137.7 \pm 5.5$ \\
\hline $\mathrm{K}+(\mathrm{mmol} / \mathrm{L})$ & $4.0 \pm 0.8$ & $4.1 \pm 0.8$ \\
\hline $\mathrm{Cl}-(\mathrm{mmol} / \mathrm{L})$ & $96.3 \pm 10.5$ & $97.0 \pm 8.4$ \\
\hline Parameters $($ admission$)$ & & \\
\hline Temperature $\left({ }^{\circ} \mathrm{C}\right)$ & $37.2 \pm 1.0$ & $37.4 \pm 1.1$ \\
\hline Systolic Blood Pressure & $145.3 \pm 108.8$ & $134.4 \pm 26.1$ \\
\hline Diastolic Blood Pressure & $76.2 \pm 14.4$ & $75.0 \pm 15.4$ \\
\hline Heart rate & $88.6 \pm 18.1$ & $91.1 \pm 19.7$ \\
\hline O2 saturation (blood gases) & $95.0 \pm 2.3$ & $93.7 \pm 5.6$ \\
\hline Second hospitalization $(\mathrm{N}, \%)$ & $9(8.2)$ & $24(8.7)$ \\
\hline
\end{tabular}

Table 2 footnotes: Abbreviations: $\mathrm{CPK}=$ creatin phosphokinase; $\mathrm{CRP}=\mathrm{C}$-reactive Protein; $\mathrm{CT}=$ computed tomography; COVID-19=coronavirus disease 2019; GGT=gamma-GT; GOT, GPT=transaminases; $\mathrm{LDH}=$ lactate dehydrogenase; ICU=intensive care unit; $\mathrm{SD}=$ standard deviation.

\section{Prevalence of Olfactory Dysfunction}

Among the 2,581 patients, 1,916 reported self-reported OD (74.2\%). The prevalence of self-reported OD was $85.9 \%, 4.5 \%$ and $6.9 \%$ in mild, moderate and severe-to-critical patients, respectively $(p=0.001)$. The clinical presentation significantly varied between mild and moderate-to-critical patient groups. Patients with moderate-to-critical COVID-19 were older than patients with mild COVID-19 $(p=0.001)$. Moderate-tocritical forms had higher prevalence of the following comorbidities: hypertension, diabetes, gastric disorders, renal, respiratory, heart, liver and neurological disorders $(p<0.05)$. Among the usual symptoms, OD was more prevalent in mild form compared with moderate-to-severe forms $(p=0.001)$. Severe and critical COVID-19 patients had more frequently cough (severe and critical), dyspnea and fever than the others $(p<0.05)($ Table 1$)$.

\section{Evolution of Subjective Olfactory Dysfunction}

Among the patients with OD, 1,363 (71.1\%) completed the follow-up subjective evaluations (Fig. 1). The high majority of these patients had mild COVID-19 form (98.0\%). Their clinical and olfactory features are described in Table 3. The most prevalent comorbities were hypertension (8.4\%), asthma (6.5\%) and gastroesophageal disorders (5.0\%). According to our clinical tools (National Health and Nutrition 
Examination Survey and SNOT-22), the most prevalent symptoms of patients were asthenia, headache and rhinorrhea. OD consisted of self-reported total loss of smell in $81.6 \%$ of patients, while $18.4 \%$ of patients reported partial loss of smell (Table 3). The mean duration of COVID-19 symptoms (excluding OD) was $13.8 \pm 6.1$ days. The OD developed after the other symptoms in $44.7 \%$ of cases and disappeared within the month following the onset of OD in $54.3 \%$ of patients. Dysgeusia, defined as the impairment of salty, sweet, bitter and sour, was reported by $55.9 \%$ of patients, whereas $83.9 \%$ of patients reported aroma perception dysfunction (Table 3 ). A total of 328 patients $(24.5 \%$ ) did not subjectively recover olfaction 60 days after the onset of the dysfunction. The mean duration of self-reported OD was $21.6 \pm 17.9$ days. 
Table 3

General and Olfactory Subjective Outcomes of COVID-19 Patients.

\begin{tabular}{|c|c|}
\hline Characteristics & All Patients $(\mathrm{N}=1363)$ \\
\hline Age (y - Mean; SD) & $41.9 \pm 13.0$ \\
\hline Gender (F/M) & $885 / 478$ \\
\hline Current Smoker & $156(11.4)$ \\
\hline History of seasonal allergy & $286(21.0)$ \\
\hline \multicolumn{2}{|l|}{ General Symptoms (N - \%) } \\
\hline Asthenia & $1176(86.3)$ \\
\hline Headache & $952(69.9)$ \\
\hline Myalgia & $861(63.2)$ \\
\hline Anorexia & $762(55.9)$ \\
\hline Cough & $715(52.5)$ \\
\hline Arthralgia & $631(46.3)$ \\
\hline Fever $\left(>38 \mathrm{C}^{\circ}\right)$ & $584(42.9)$ \\
\hline Diarrhea & $565(41.5)$ \\
\hline Dyspnea & $505(37.1)$ \\
\hline Abdominal pain & $362(26.6)$ \\
\hline Nausea, vomiting & $322(23.6)$ \\
\hline Sticky mucus/phlegm & $280(20.5)$ \\
\hline \multicolumn{2}{|c|}{ Ear, nose and throat Sympotms (N - \%) } \\
\hline Self-reported anosmia & $1112(81.6)$ \\
\hline Rhinorrhea & $878(64.4)$ \\
\hline Nasal obstruction & $846(62.1)$ \\
\hline Taste dysfunction & $762(55.9)$ \\
\hline Postnasal drip & 715 (52.5) \\
\hline Sore throat & $661(48.5)$ \\
\hline Face pain/heaviness & $656(48.1)$ \\
\hline Ear pain & $531(39.0)$ \\
\hline Dysphonia & $525(38.5)$ \\
\hline
\end{tabular}




\begin{tabular}{|ll|}
\hline Characteristics & All Patients (N=1363) \\
\hline Dysphagia & $325(23.8)$ \\
\hline Self-reported hyposmia & $251(18.4)$ \\
\hline Aroma Sense Dysfunction (retro-olfaction) & \\
\hline Total loss of aroma perception sense & $225(16.5)$ \\
\hline Partial loss of aroma & $777(57.0)$ \\
\hline Distortion & $142(10.4)$ \\
\hline No problem & $136(10.0)$ \\
\hline Missing Data & $83(6.1)$ \\
\hline Smell Dysfunction & \\
\hline Cacosmia & $921(67.6)$ \\
\hline Phantosmia & $224(16.4)$ \\
\hline Onset of Smell Dysfunction & $\mathrm{N}=1339$ \\
\hline Before the other symptoms & $225(16.8)$ \\
\hline Concomittant with other symptoms & $439(32.8)$ \\
\hline After the other symptoms & $599(44.7)$ \\
\hline Did not remember/Missing data & $76(5.7)$ \\
\hline Smell Dysfunction Duration & $21.6 \pm 17.9$ \\
\hline $1-4$ days & $157(11.7)$ \\
\hline $5-8$ days & $172(15.9)$ \\
\hline $9-14$ days & $186(13.9)$ \\
\hline $15-30$ days & $(11.4)$ \\
\hline $31-45$ days & \\
\hline $45-60$ days & \\
\hline Unresolved & \\
\hline Mean duration (Mean, SD, days) & \\
\hline
\end{tabular}

Table 3 footnotes: Abbreviations: $F / M=$ female/male; $N=$ number; $S D=$ standard deviation.

Prevalence and Evolution of Objective Olfactory Dysfunction 
Among the 2,581 patients, 233 patients completed objective olfactory evaluations (Table 4). There were 52 patients with moderate-to-critical COVID-19 and 181 patients with mild form of the disease $(77.7 \%)$. Self-reported anosmia, cacosmia, phantosmia and aroma dysfunction were significantly more prevalent in mild than moderate-to-critical COVID-19 forms $(p<0.02)$. The mean values of the Sniffin'Sticks tests were significantly lower in mild patient group compared with moderate-to-critical patient group $(p=0.001$; Table 5). Moreover, the prevalence of objective olfactory dysfunction was significantly higher in mild forms compared with moderate-to-critical forms (36.6 versus $54.7 ; p=0.001)$. 
Table 4

Clinical Characteristics of Patients who benefited from Objective Olfactory Evaluations.

\begin{tabular}{|c|c|c|c|c|}
\hline \multirow[t]{3}{*}{ Characteristics } & All patients with & $\begin{array}{l}\text { Patient with } \\
\text { Mild }\end{array}$ & $\begin{array}{l}\text { Patient with } \\
\text { MC }\end{array}$ & Differences \\
\hline & $\begin{array}{l}\text { Objective } \\
\text { Evaluation }\end{array}$ & $\begin{array}{l}\text { COVID-19 } \\
\text { Form }\end{array}$ & $\begin{array}{l}\text { COVID-19 } \\
\text { Form }\end{array}$ & Mild vs MC \\
\hline & $(\mathrm{N}=233)$ & $(\mathrm{N}=181)$ & $(\mathrm{N}=52)$ & $p$-value \\
\hline Age (y - Mean; SD) & $46.0 \pm 14.3$ & $42.4 \pm 12.7$ & $59.0 \pm 12.7$ & 0.001 \\
\hline Gender (F/M) & $154 / 79$ & $126 / 55$ & $28 / 24$ & 0.035 \\
\hline Current Smoker & $15(6.4)$ & $14(7.7)$ & $1(1.9)$ & NS \\
\hline History of seasonal allergy & $41(17.6)$ & 28 (15.5à & $13(25.0)$ & NS \\
\hline \multicolumn{5}{|l|}{ Comorbidities } \\
\hline Hypothyroidism & $21(9.0)$ & $10(5.5)$ & $11(21.2)$ & 0.001 \\
\hline Hypertension & $30(12.9)$ & $13(7.2)$ & $17(32.7)$ & 0.001 \\
\hline Asthma & $20(8.6)$ & $12(6.6)$ & $8(15.4)$ & NS \\
\hline Reflux & $30(12.9)$ & $20(11.0)$ & $10(19.2)$ & NS \\
\hline Depression & $2(0.9)$ & $1(0.6)$ & $1(1.9)$ & NS \\
\hline Diabetes & $19(8.2)$ & $7(3.9)$ & $12(23.1)$ & 0.001 \\
\hline Heart problems & $13(5.6)$ & $5(2.8)$ & $8(15.4)$ & 0.002 \\
\hline Liver Insuffisiency & $3(1.3)$ & $2(1.1)$ & $1(1.9)$ & NS \\
\hline Kidney Insuffisiency & $3(1.3)$ & $0(0)$ & $3(5.8)$ & 0.012 \\
\hline Respiratory insuffisiency & $2(0.9)$ & $1(0.6)$ & $1(1.9)$ & NS \\
\hline Neurological Disease & $2(0.9)$ & $0(0)$ & $2(3.8)$ & NS \\
\hline \multicolumn{5}{|l|}{ General Symptoms (N - \%) } \\
\hline Asthenia & $183(78.5)$ & $137(75.7)$ & $46(88.5)$ & 0.001 \\
\hline Headache & $147(63.1)$ & $114(63.0)$ & $33(63.5)$ & NS \\
\hline Myalgia & $131(56.2)$ & $96(53.0)$ & $35(67.3)$ & 0.001 \\
\hline Anorexia & $131(56.2)$ & $85(47.0)$ & $46(88.5)$ & 0.001 \\
\hline Cough & $130(55.8)$ & $91(50.3)$ & $39(75.0)$ & 0.001 \\
\hline Arthralgia & $104(44.6)$ & $77(42.5)$ & $27(51.9)$ & 0.035 \\
\hline Fever (> 38C) & $109(46.8)$ & $62(34.3)$ & $47(90.4)$ & 0.001 \\
\hline
\end{tabular}




\begin{tabular}{|lllll|}
\hline Characteristics & All patients with & $\begin{array}{l}\text { Patient with } \\
\text { Mild }\end{array}$ & $\begin{array}{l}\text { Patient with } \\
\text { MC }\end{array}$ & Differences \\
\cline { 2 - 5 } & $\begin{array}{l}\text { Objective } \\
\text { Evaluation }\end{array}$ & $\begin{array}{l}\text { COVID-19 } \\
\text { Form }\end{array}$ & $\begin{array}{l}\text { COVID-19 } \\
\text { Form }\end{array}$ & Mild vs MC \\
\hline Diarrhea & $105(45.1)$ & $73(40.3)$ & $32(61.5)$ & 0.001 \\
\hline Dyspnea & $106(45.5)$ & $64(35.4)$ & $42(80.8)$ & 0.001 \\
\hline Abdominal pain & $78(33.5)$ & $59(32.6)$ & $19(36.5)$ & NS \\
\hline Nausea, vomiting & $74(31.8)$ & $50(27.6)$ & $24(46.2)$ & 0.001 \\
\hline Sticky mucus/phlegm & $87(37.3)$ & $65(35.9)$ & $22(42.3)$ & NS \\
\hline $\begin{array}{l}\text { Ear, nose and throat Sympotms } \\
\text { (N - \%) }\end{array}$ & & & & \\
\hline Self-reported anosmia & $91(39.1)$ & $77(42.5)$ & $14(26.9)$ & 0.008 \\
\hline Rhinorrhea & $128(54.9)$ & $94(51.9)$ & $34(65.4)$ & 0.018 \\
\hline Nasal obstruction & $134(57.5)$ & $105(58.0)$ & $29(55.8)$ & NS \\
\hline Taste dysfunction & $51(21.9)$ & $42(23.2)$ & $9(17.3)$ & NS \\
\hline Postnasal drip & $111(47.6)$ & $90(49.7)$ & $21(40.4)$ & NS \\
\hline Sore throat & $82(35.2)$ & $62(34.3)$ & $20(38.5)$ & NS \\
\hline Face pain/heaviness & $77(33.0)$ & $64(35.4)$ & $13(25.0)$ & NS \\
\hline Ear pain & $81(34.8)$ & $69(38.1)$ & $12(23.1)$ & NS \\
\hline Dysphonia & $91(39.1)$ & $67(37.0)$ & $24(46.2)$ & 0.019 \\
\hline Dysphagia & $63(27.0)$ & $45(24.9)$ & $18(34.6)$ & 0.001 \\
\hline Self-reported hyposmia & $66(28.3)$ & $53(29.3)$ & $13(25.0)$ & 0.008 \\
\hline
\end{tabular}

Table 4 footnotes: *Because some patients were in critical condition (intubated), 33.3\% of severe patients did not remember or could not determine the time of the onset of olfactory dysfunction. Abbreviations: $\mathrm{MC}=$ moderate-to-critical; NS=non significant; $\mathrm{SD}=$ standard deviation. 
Table 5

Olfactory Outcomes of Patients who benefited from Objective Olfactory Evaluations.

\begin{tabular}{|c|c|c|c|c|}
\hline \multirow[t]{3}{*}{ Characteristics } & All patients with & $\begin{array}{l}\text { Patient with } \\
\text { Mild }\end{array}$ & $\begin{array}{l}\text { Patient with } \\
\text { MC }\end{array}$ & Differences \\
\hline & $\begin{array}{l}\text { Objective } \\
\text { Evaluation }\end{array}$ & $\begin{array}{l}\text { COVID-19 } \\
\text { Form }\end{array}$ & $\begin{array}{l}\text { COVID-19 } \\
\text { Form }\end{array}$ & Mild vs MC \\
\hline & $(\mathrm{N}=233)$ & $(\mathrm{N}=181)$ & $(N=52)$ & $p$-value \\
\hline SNOT-22 (Mean, SD) & $33.5 \pm 20.6$ & $32.9 \pm 20.4$ & $35.3 \pm 21.4$ & NS \\
\hline \multicolumn{5}{|l|}{$\begin{array}{l}\text { Aroma Sense Dysfunction (retro- } \\
\text { olfaction) }\end{array}$} \\
\hline $\begin{array}{l}\text { Total loss of aroma perception } \\
\text { sense }\end{array}$ & $44(18.9)$ & $39(21.5)$ & $5(9.6)$ & 0.001 \\
\hline Partial loss of aroma & $48(20.6)$ & $44(24.3)$ & $4(7.7)$ & 0.001 \\
\hline Distortion & $18(7.7)$ & $16(8.8)$ & $2(3.8)$ & 0.001 \\
\hline \multicolumn{5}{|l|}{ Smell Dysfunction } \\
\hline Cacosmia & $115(49.4)$ & 108 (59.7) & $7(13.5)$ & 0.005 \\
\hline Phantosmia & $33(14.2)$ & $31(17.1)$ & $2(3.8)$ & 0.019 \\
\hline Onset of Smell Dysfunction & 157 & $N=130$ & $N=27$ & \\
\hline Before the other symptoms & $25(15.9)$ & $23(17.7)$ & $2(7.4)$ & \multirow[t]{3}{*}{ NS } \\
\hline $\begin{array}{l}\text { Concomittant with other } \\
\text { symptoms }\end{array}$ & $51(32.5)$ & $43(33.1)$ & $8(29.6)$ & \\
\hline After the other symptoms & $72(45.9)$ & $64(49.2)$ & $8(29.6)$ & \\
\hline $\begin{array}{l}\text { Did not remember/Cannot } \\
\text { determine* }\end{array}$ & $9(5.7)$ & $0(0)$ & 9 (33.3) & \\
\hline Objective Olfactory Tests & & $N=181$ & $N=52$ & \\
\hline Anosmia & $75(32.2)$ & $63(34.8)$ & $12(23.1)$ & \multirow[t]{3}{*}{0.001} \\
\hline Hyposmia & $43(18.4)$ & $36(19.9)$ & $7(13.5)$ & \\
\hline Normosmia & $115(49.4)$ & $82(45.3)$ & $33(63.5)$ & \\
\hline Sniffin'Sticks Test (Mean, SD) & $10.5 \pm 3.7$ & $9.9 \pm 3.7$ & $12.3 \pm 3.2$ & 0.001 \\
\hline Serology (IgG level) & $91.3 \pm 84.2$ & $54.5 \pm 41.4$ & $168.2 \pm 75.1$ & 0.001 \\
\hline
\end{tabular}

Table 5 footnotes: *Because some patients were in critical condition (intubated), $33.3 \%$ of severe patients did not remember or could not determine the time of the onset of olfactory dysfunction. Abbreviations: 
$\mathrm{MC}=$ moderate-to-critical; NS=non significant; $\mathrm{SD}=$ standard deviation; $\mathrm{SNOT}-22=$ sino-nasal outcome-22 questionnaire.

The baseline mean value of Sniffin-Sticks tests of anosmic and hyposmic patients $(N=118 ; 7.6 \pm 3.0)$ significantly improved after $30(10.6 \pm 3.7)$ and 60 days $(11.3 \pm 3.5)$ of follow-up $(p=0.001)$. At the end of follow-up, 18 anosmic/hyposmic patients did not objectively fully recover olfaction (15.3\%).

\section{Clinical and Objective Olfactory Associations}

Among the cohort of 2,581 patients, there were no significant association between clinical data (biology, CT-scan findings) and the development of OD.

Among the cohort of 233 patients, individuals with fever exhibited a significantly higher level of IgG $\left(r_{s}=0.521 ; p=0.001\right)$. The Sniffin-Sticks test value was positively associated with the patient age $\left(r_{s}=0.246 ; p=0.001\right)$. There was no significant association between nasal symptom severities; the occurrence of self-reported OD and the result of the objective olfactory testing. The higher baseline severity of olfactory loss measured using the Sniffin-Sticks was strongly predictive of 2-month persistent loss $(p<0.001)$. The level of IgG was positively correlated with the Sniffin-Sticks test in the entire cohort $\left(r_{s}=0.395 ; p=0.003\right)$.

\section{Discussion:}

Loss of smell is a key symptom of the coronavirus disease 2019, which may be isolated symptom or associated with other general and otolaryngological symptoms. The majority of studies that investigated OD in COVID-19 included mild patients, $2,4,7,11-13$ which raised the issue of the specificity and the predictive value of $O D$ on the severity of the infection.

In this study, we observed that both self-reported and objective ODs were more prevalent in mild patients compared with individuals presenting moderate-to-critical COVID-19. Vaira et al. recently observed that anosmia and hyposmia accounted for $70 \%$ of COVID-19 mild-to-moderate patients. ${ }^{5}$ However, they only observed a trend of significant differences between severe and mild forms regarding the objective olfactory disorder. In the study of Moein et al. 60 COVID-19 hospitalized and home-managed patients benefited from objective olfactory evaluations. ${ }^{14}$ Using a different anosmia definition (microsmia), the authors reported a prevalence of objective OD in $98 \%$ of patients. Although a low number of hospitalized patients $(\mathrm{N}=6)$, the study findings support a higher prevalence of OD in mild patients (45\%) compared with severe patients (10\%). ${ }^{14}$ The comparison with these two studies is however limited because authors did not classify the patients according to the WHO classification and they used different olfactory tests.

The main hypothesis underlying the higher prevalence of anosmia in mild COVID-19 would consist of differences in the immune response to the infection in mild and moderate-to-critical patients. In this hypothesis, patients with mild COVID-19 could have a better local immunological response through a higher production of IgA, which could limit the virus spread into the organism. The limited virus spread in 
the host body could therefore be associated with a mild clinical form of the disease. Due to the local inflammatory reaction and the well-demonstrated olfactory cell expression of Angiontensin Coverting Enzyme-2 (ACE2) and TMPRSS2, ${ }^{15,16}$ the patients with mild disease could have stronger impairment of olfactory cells. In addition, we observed that severe and critical patients had a significantly higher level of IgG than mild patients, which may corroborate some findings of the literature. ${ }^{17}$ However, this hypothesis requires additional studies involving immunological sera, saliva, and nasal secretion analyses.

According to our analysis, young patients could have a higher rate of anosmia compared with elderly individuals. Similar findings have been reported in the study of Speth et al. who investigated self-reported OD in 103 COVID-19 patients. ${ }^{18}$ Although a significant p-value, we need to remain cautious in the interpretation of this results for two reasons. On the one hand, the association is significant but exhibited a low correlation coefficient $\left(r_{s}=0.246\right)$.

The high prevalence of OD in COVID-19 patients supports the need for primary care, ear, nose, and throat (ENT) and neurology physicians to be able to counsel patients regarding the likelihood of recovery, and to identify those at risk of persistent OD, such that therapeutic strategies can be targeted appropriately. Considering both subjective and objective data, we may suggest that the 60-day recovery rate ranges from $75-85 \%$. Interestingly, we may identify several profiles of OD severity because over a third of patients reported smell recovery within the 14 days following the development of OD, while one third did not recover within the 45 days. Typically, OD occurring as part of the common cold is related to nasal congestion, rhinorrhea, olfactory cleft edema and lasts 2-3 weeks. The high prevalence of nasal symptoms could partly explain the occurrence of short OD in some patients who rapidly recovered olfaction once the nasal symptoms disappeared. However, for patients with mid-to-long term or persistent $\mathrm{OD}$, the pathophysiological mechanisms underlying the development of OD could be more complex. According to recent findings, ${ }^{15,19}$ the OD could be additionally associated with injury of the olfactory neuroepithelial and a virus spread into the olfactory bulb where sustentorial cells and; in some patients, stem neurons express ACE2 and TMPRSS2. Because the expression of ACE2 and TMPRSS2 varies between individuals, ${ }^{20}$ the long duration of OD in some patients could be due to higher protein expression and more extensive injuries of the olfactory cells. The neurogenesis of the olfactory cells is possible but may take several months. ${ }^{21}$ The neural hypothesis of OD related to COVID-19 infection is supported by the lack of significant association between olfactory evaluation results and nasal complaints. Moreover, post-viral anosmia was observed in some infections related to viruses of the Coronaviridae family. ${ }^{22}$

In sum, the mechanisms underlying the OD development could associate olfactory cleft congestion in short-term anosmic patients, injury of the olfactory neuroepithelium and virus spread into the olfactory bulb in mid-to-long terms anosmic patients. Future studies are needed to confirm these hypotheses.

The present study has several strengths and limitations. The main strength is the high number of included patients, which allows to confirm the higher prevalence of OD in mild over moderate-to-critical patients. The data collected in this large cohort allowed us to evaluate the 2-month subjective and objective recovery rate of smell sense. The main limitations are the lack of clinical olfactory examination 
or imaging at the onset of the disease to assess the olfactory cleft and the olfactory bulb. These observations could provide useful information to better understand the pathophysiological mechanisms underlying the development of anosmia. However, performing nasal fiberoptic examination during the pandemic was prohibited. Moreover, the taste evaluations reported low rates of taste dysfunction in hospitalized patients. Many severe-to-critical patients had nasogastric feeding tube, which, additionally to the delay to assess taste function, may bias the assessment of taste dysfunction. Another limitation is related to the delay ( 2 to 3 weeks) between the OD onset and the realization of the olfactory evaluations. This delay was particularly long in hospitalized patients who had to be able to undergo olfactory evaluations. Although this possibility is not supported by patient-reported symptoms, the delay between the onset of symptoms and the objective olfactory testing may underestimate the incidence of olfactory dysfunction.

\section{Conclusion}

OD is a prevalent disorder in COVID-19 patients with a higher prevalence in patients with mild forms of the disease. At the 2 months follow-up, 75-85\% of patients recovered olfaction according to subjective and objective olfactory evaluations. Future studies are needed to determine the long-term recovery rate of COVID-19 patients.

\section{Declarations}

\section{Acknowledgments: N/A.}

Competing interests: None. Sponsorships: None. Funding source: None.

\section{Author contribution:}

Study concept and design: Lechien, Ducarme, Chiesa, Saussez, Beckers, Mustin.

Acquisition, analysis, or interpretation of data: Lechien, Saussez, Jouffe, Beckers, Mustin, Ducarme, Marchant.

Drafting of the manuscript: Lechien, Saussez, Hans, Marchant.

Critical revision of the manuscript for important intellectual content: Saussez, Chiesa, Jouffe, Journe, Hans, Marchant.

Materials \& Correspondence: Jerome R. Lechien.

\section{References}

1. WHO website. www.who.int/docs Consulted June 24, 2020. 
2. Lechien JR, Chiesa-Estomba CM, Hans S, Barillari MR, Jouffe L, Saussez S. Loss of Smell and Taste in 2,013 European Mild-to-Moderation COVID-19 Patients. Accepted for publication in Ann Int Med. 2020.

3. Zhang X, Tan Y, Ling Y, et al. Viral and host factors related to the clinical outcome of COVID-19. Nature. 2020. doi: 10.1038/s41586-020-2355-0.

4. Hopkins C, Surda P, Kumar N. Presentation of new onset anosmia during the COVID-19 pandemic. Rhinology. 2020; 58(3):295-298. doi: 10.4193/Rhin20.116.

5. Angelo Vaira L, Hopkins C, Salzano G, et al. Olfactory and gustatory function impairment in COVID19 patients: Italian objective multicenter-study. Head Neck. 2020. doi: 10.1002/hed.26269.

6. World Health Organization, 2020. Clinical Management of COVID-19: interim guidance, 27 may 2020 (No. WHO/2019-nCoV/clinical/2020.5). World Health Organization.

7. Lechien JR, Cabaraux P, Chiesa-Estomba CM, et al. Objective olfactory evaluation of self-reported loss of smell in a case series of 86 COVID-19 patients. Head Neck. 2020 May 21. doi: 10.1002/hed.26279.

8. Bhattacharyya N, Kepnes LJ. Contemporary assessment of the prevalence of smell and taste problems in adults. Laryngoscope. 2015; 125:1102-6. doi: 10.1002/lary.24999.

9. Hummel T, Kobal G., Gudziol H et al. Normative data for the "Sniffın' Sticks" including tests of odor identification, odor discrimination, and olfactory thresholds: an upgrade based on a group of more than 3,000 subjects. Eur Arch Otorhinolaryngol 2007; 264:237-243. https://doi.org/10.1007/s00405006-0173-0.

10. de Dorlodot C, Horoi M, Lefebvre P, Collet S, Bertrand B, Eloy P, Poirrier AL. French adaptation and validation of the sino-nasal outcome test-22: a prospective cohort study on quality of life among 422 subjects. Clin Otolaryngol. 2015; 40(1):29-35. doi: 10.1111/coa.12315.

11. 10.1016/j.medmal.2020.04.006

Klopfenstein T, Kadiane-Oussou NJ, Toko L, Royer PY, Lepiller Q, Gendrin V, Zayet S. Features of anosmia in COVID-19. Med Mal Infect. 2020: S0399-077 × (20)30110-4. doi:

10.1016/j.medmal.2020.04.006.

12. Lechien JR, Chiesa-Estomba CM, De Siati DR, et al. Olfactory and gustatory dysfunctions as a clinical presentation of mild-to-moderate forms of the coronavirus disease (COVID-19): a multicenter European study. Eur Arch Otorhinolaryngol. 2020. doi: 10.1007/s00405-020-05965-1.

13. Lee Y, Min P, Lee S, Kim SW. Prevalence and Duration of Acute Loss of Smell or Taste in COVID-19 Patients. J Korean Med Sci. 2020; 35(18):e174. doi: 10.3346/jkms.2020.35.e174.

14. Moein ST, Hashemian SMR, Mansourafshar B, Khorram-Tousi A, Tabarsi P, Doty RL. Smell dysfunction: a biomarker for COVID-19. Int Forum Allergy Rhinol. 2020. doi: 10.1002/alr.22587.

15. Brann DH, Tsukahara T, Weinreb C et al. Non-neuronal expression of SARS-CoV-2 entry genes in the olfactory system suggests mechanisms underlying COVID-19-associated anosmia. Preprint. https://doi.org/10.1101/2020.03.25.009084. 
16. Ou X, Liu Y, Lei X, et al. Characterization of spike glycoprotein of SARS-CoV-2 on virus entry and its immune cross-reactivity with SARS-CoV. Nat Commun. 2020; 11(1):1620. doi: 10.1038/s41467-02015562-9.

17. Ozturk T, Howell C, Benameur K, et al. Cross-sectional IgM and IgG profiles in SARS-CoV-2 infection. medRxiv. 2020 May 14:2020.05.10.20097535. doi: 10.1101/2020.05.10.20097535.

18. Speth MM, Singer-Cornelius T, Obere M, Gengler I, Brockmeier SJ, Sedaghat AR. Olfactory Dysfunction and Sinonasal Symptomatology in COVID-18: Prevalence, Severity, Timing, and Associated Characteristics. Otolaryngol Head Neck Surg. 2020: 194599820929185. doi: $10.1177 / 0194599820929185$.

19. Chen M, Shen W, Rowan NR, Kulaga H, Hillel A, Ramanathan M Jr, Lane AP. Elevated ACE2 expression in the olfactory neuroepithelium: implications for anosmia and upper respiratory SARS-CoV-2 entry and replication. bioRxiv. 2020: 2020.05.08.084996. doi: 10.1101/2020.05.08.084996.

20. Chetrit A, Lechien JR, Ammar A, et al. Magnetic Resonance Imaging of Olfactory Structures in COVID19 Patients: Preliminary Report. Submitted to Clin Microbiol Infect. 2020.

21. Cao Y, Li L, Feng Z, Wan S, Huang P, Sun X, Wen F, Huang X, Ning G, Wang W. Comparative genetic analysis of the novel coronavirus (2019-nCoV/SARS-CoV-2) receptor ACE2 in different populations. Cell Discov. 2020; 6:11. doi: 10.1038/s41421-020-0147-1.

22. Lazarini F, Lledo PM. Is adult neurogenesis essential for olfaction? Trends Neurosci. 2011 Jan;34(1):20-30. doi: 10.1016/j.tins.2010.09.006.

\section{Figures}


Laboratory Database of European Hospitals (RT-PCR) ${ }^{1}$

\section{Inclusion Criteria:}

1. Laboratory-confirmed COVID-19 (+RT-PCR)

2. Ambulatory or Hospitalized patients

Patient Participation Agreement \& Electronic Consent

Patients $(\mathrm{N}=\mathbf{2 , 5 8 1})$

Mild $(\mathrm{N}=2,194)-$ Moderate $(\mathrm{N}=110)-$ Severe-to-critical $(\mathrm{N}=277)$

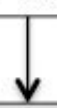

Clinical \& Epidemiological Data Extraction: Survey Monkey ${ }^{2}$

Evaluation of Self-reported Olfactory Dysfunction $(\mathbf{N}=\mathbf{2 , 5 8 1})^{\mathbf{3}}$

Mild (85.9\%) - Moderate (4.5\%) - Severe-to-critical (6.9\%)

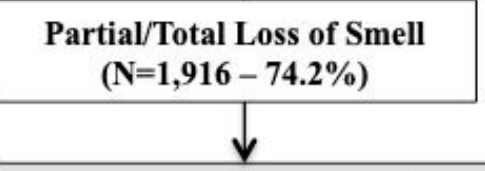

Completed 2-month Evaluations ${ }^{4}$ ( $\mathrm{N}=\mathbf{1 , 3 6 3}$ patients $-71.1 \%)$

Hospitalized Patients $(2.0 \%)$

Ambulatory Patients (98.0\%)

$>60$ days Subjective

Unrecovery: $24.5 \%$

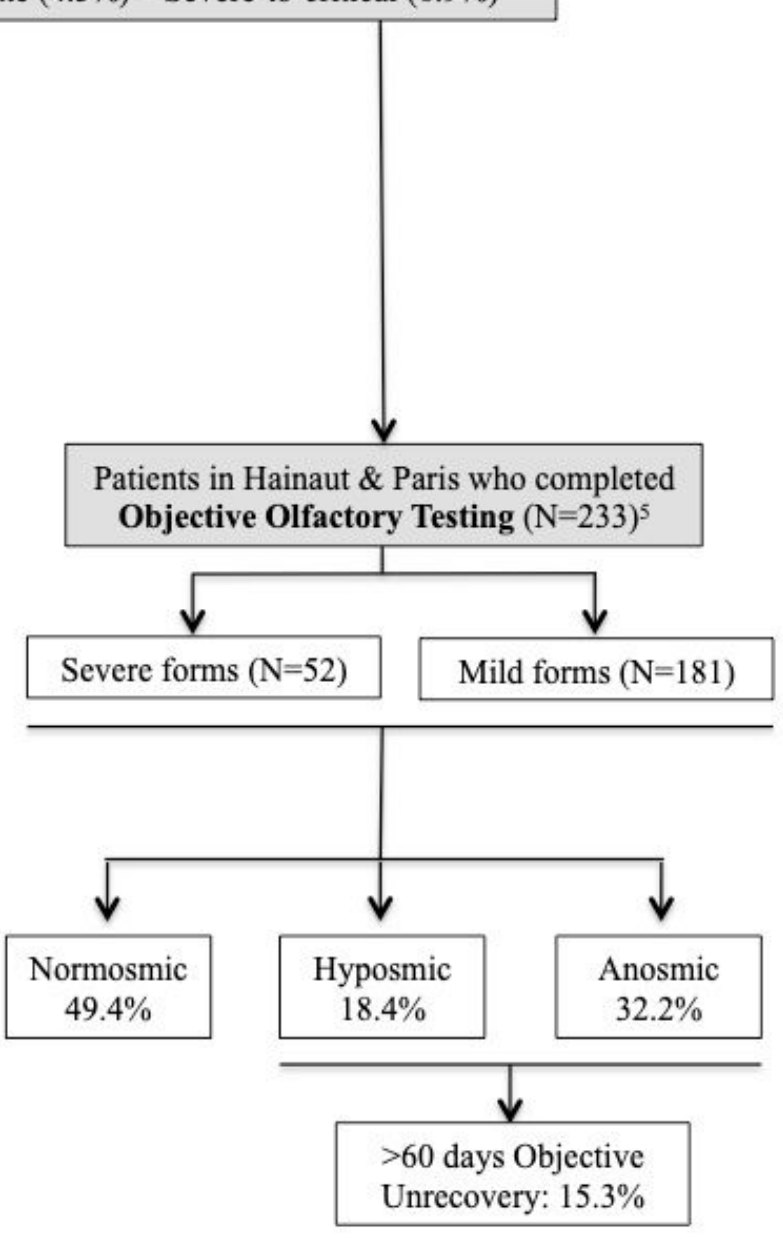

\section{Figure 1}

Flow Chart. 1The diagnosis tests of ambulatory and hospitalized patients were centralized in Hospital Laboratories, allowing the identification of patients with a positive diagnosis. 2Physicians directly completed patient information on an online questionnaire for hospitalized patients while ambulatory patients fulfilled the evaluation at home (home-managed patients). 3The first objective of the study was to investigate the prevalence of olfactory dysfunction according to the severity of the disease $(\mathrm{N}=2,581)$. 
4The second objective of the study was to investigate the recovery of olfaction, which was made on 1,363 patients who completed the evaluations. To be included, patients had to be followed over the 60 days post-COVID-19 to assess (potential) occurrence and evolution of olfactory dysfunction. 5The third objective of the study was to objectively assess the olfactory dysfunction in a subset of patients of the 2,581 included patients. Abbreviations: COVID-19= coronavirus disease 2019; RT-PCR= reverse transcription polymerase chain reaction. 